\title{
Impulse tests to determine the mechanical properties of aluminum alloys used to manufacture auto rims
}

\author{
Eva Nyaguly $^{1 *}$, Sorin Deac $^{2}$, Ion Crâş̧tiu ${ }^{3}$, Dorin Simoiu ${ }^{4}$,Teodor Hepuţ ${ }^{5}$ and Liviu Bereteu ${ }^{6}$ \\ ${ }^{1}$ Politehnica University Timisoara, pintiutza@gmail.com, Romania \\ ${ }^{2}$ Politehnica University Timisoara, sorin.deac@upt.ro, Romania \\ ${ }^{3}$ Politehnica University Timisoara, ion.crastiu@upt.ro, Romania \\ ${ }^{4}$ Politehnica University Timisoara, dorin.simoiu@upt.ro, Romania \\ ${ }^{5}$ Politehnica University Timisoara, teodor.heput@upt.ro, Romania \\ ${ }^{6}$ Politehnica University Timisoara, liviu.bereteu@upt.ro, Romania
}

\begin{abstract}
The purpose of this paper is to analyze the improvement of quality rims made of different aluminum alloys for road vehicles. The modulus of elasticity, shear modulus and Poisson's ratio are mechanical parameters that characterize, together with mass and geometrical dimensions, dynamic behavior of auto rims. To reduce the weight of the rims, the steel is replaced with the aluminum and magnesium alloys or composite materials. The natural frequencies and the shape of the natural modes are determined for different aluminum samples, using the Finite Element Method and Modal Analysis in the ANSYS software. The vibroacoustic signal is recorded through a condenser microphone that has a high fidelity in the audible range of 20-20,000 $\mathrm{Hz}$. The vibration responses of the aluminium specimens, in free-free conditions, are carried out using algorithms based on Fast Fourier Transform (FFT), and Prony's series.
\end{abstract}

\section{Introduction}

After iron, aluminum is now the second most widely used metal in the world. Aluminum and its alloys have become widely used metals in recent decades, mainly due to their properties, among which the most important are: densities and thus low weight, high strength, high resistance to corrosion, easy mechanical processing etc. It is noteworthy that aluminum has a very good weldability and not least, the best property is its high rate of recycling.

The popularity of aluminum and its alloys derive from its use in various areas such as: first of all in machine construction, automotive, food industry, chemical industry, civil construction, shipbuilding and aerospace industry, railway transport industry, areas where the use of aluminum is substantial.

In the commercial process, this material is called unalloyed aluminum. It is very easy to be processed, it has very good anticorrosive properties, it can be anodized and painted, and it can be varnished. It also has excellent bending properties and excellent weldability properties. It is used to various surfaces in advertising production, or it is used frequent in common surfaces plating.
In the use of unalloyed aluminum, the main issue that it is considered is that in the corrosion process, the surface does not become matt. This material can be very well anodized in the natural state or in the painted state. Anodized sheets not only looks much better in terms of aesthetics, but also presents much better features anticorrosive and erosion properties than the natural aluminum. These can be maintain and clean up much easier.

Aluminium and its alloys have increased machinability characteristics: can be excellent processed by lathering and these have a good weldability with the MIG/WIG procedures. For these reasons, these materials are widespread in industrial applications, including shipbuilding, as shown T. Anderson in paper [1]. The arc welding method - MIG is the most common method of joining aluminum alloys used in shipbuilding, and the research results on the mechanical properties of aluminium alloys and its MIG welded joints were carried out using a static tensile test by K. Dudzik [2]. .

To achieve the new fuel efficiency standards requires the use of vehicle weight reduction. Achieving this goal involves the use of new materials and alloys. Aluminium alloy 6082, according to SR 1706: 2000 is such alloy and is used in manufacturing car rims by hot plastic deformation [3]. Performance rims are closely related to the mechanical properties of the material, and any

\footnotetext{
*Corresponding author: pintiutza@gmail.com
} 
chemical composition changing, in order to improve the structure of aluminum-alloys must be found in increasing the mechanical properties values, were presented by R.Pradeep, B.S. Praveen Kumar and B. Prashanth in [4], and by N.Bularda and T. Hepuţ in [5] and [6].

In all these works, to determine the elastic properties of aluminum and its alloys were used classical methods based on shear and tensile test respectively.

In recent years a strong development took nondestructive methods based on the resonance tests to determine the elastic properties of metals and their alloys. In the paper [7], M. Alfano and L. Pagnotta reviews the latest patents in the field of non-destructive tests for the determination of mechanical characteristics of materials. The use of the vibroacoustic signals for determining the elasticity modulus of the hydroxiapatite or welded joints is presented in [8] by L. Bereteu, M. Vodă, Gh. Draganescu and in [9] by O. Suciu, L. Bereteu, Gh. Draganescu.

The purpose of this paper is to show that by analyzing a vibration signal obtained after applying a mechanical impulse on the sample can be determined all three elastic properties of the material: the longitudinal modulus (Young's), the shear modulus and the Poisson coefficient. This is possible by validating the results given by the spectrum analysis with the results of modal analysis based on Finite Element Method. For signal acquisition uses an acoustic sensor one condenser microphone and for signal processing it is used an adequate software [10].

\section{Theoretical background}

\subsection{Resonant vibration tests}

In the following, the samples consist of welded aluminum, shall be considered rectangular beam, having a constant section, and no subject to external forces. To study the free vibration of these beams can consider different boundary conditions. The best known case in the literature is free-free conditions. The elastic properties of the material can be determined by measuring the frequencies of the free vibrating bar excited by mechanical impulse. Vibratory motion of the beam is governed by a partial differential equation with partial derivate Euler-Bernoulli, as it is given by Meirovics [11].

$$
\mathbf{E I} \frac{\partial^{4} \mathbf{Y}(\mathrm{x}, \mathrm{t})}{\partial \mathbf{x}^{4}}+\rho \mathrm{A} \frac{\partial^{2} \mathbf{Y}(\mathrm{x}, \mathrm{t})}{\partial \mathrm{t}^{2}}=\mathbf{0}
$$

where $\mathrm{Y}(\mathrm{x}, \mathrm{t}), \mathrm{E}, \mathrm{I}, \mathrm{A}, \rho$ are the displacement of neutral axis of the beam at $\mathrm{x}$ distance to the left end, the longitudinal elastic modulus, geometric moment of inertia of the cross - section of the beam, the area of this section and material density. The characteristic equation for free-free boundary conditions is:

$$
1-\operatorname{ch} X \cos X=0
$$

where

$$
X=\sqrt[4]{\frac{4 \pi^{2} f^{2} L^{4} \rho \mathrm{A}}{E I}}
$$

$\mathrm{f}$ is one of the bending resonance frequencies and $\mathrm{L}$ is the length of the beam.

The first two roots of the characteristic Eq. 2 are $X_{1}=4,730, X_{2}=7,853$, and for natural modes $r>2$, it is easy to show that

$$
\mathrm{X}_{\mathrm{r}}=\frac{(2 \mathrm{r}+1) \pi}{2}
$$

From Eq. ${ }^{\circ} 3$ and Eq. ${ }^{\circ} 4$ it can obtained the relation between free vibration frequency $f_{r}$ of the sample and its Young's modulus

$$
E=\frac{4 \pi^{2} f_{r}^{2} L^{4} \rho A}{X_{r}^{4} I}
$$

This relationship is valid only for the bending modes of the sample.

By a similar procedure could be obtained the relation between the shear modulus and the corresponding resonance frequencies of the torsion modes:

$$
\mathrm{G}=\frac{4 \rho \mathrm{f}_{\mathrm{r}}^{2} \mathrm{~L}^{4} K_{f}}{\mathrm{r}^{2}},
$$

where $\mathrm{r}$ is the torsion mode number and $K_{\mathrm{f}}$ is a coefficient that takes into account the geometrical shape of cross-section and it is equal to 1 only for circular section. For a rectangular section has the expression:

$$
K_{\mathrm{f}}=\frac{\frac{\mathrm{b}}{\mathrm{h}}+\frac{\mathrm{h}}{\mathrm{b}}}{4\left(\frac{\mathrm{h}}{\mathrm{b}}\right)-2.52\left(\frac{\mathrm{h}}{\mathrm{b}}\right)^{2}+0.21\left(\frac{\mathrm{h}}{\mathrm{b}}\right)^{6}}
$$

where $b$ is the sample breadth, and the $h$ is sample thickness.

To determine Poisson's ratio noted by $v$ it is used the well-known relationship between the three mechanical parameters that characterize the behavior of a metal to simple tensile and torsion tests:

$$
v=\frac{E}{2 G}-1 \text {. }
$$

\subsection{Finite Element Analysis}

To validate the sample shape modes of vibration and correlation with experimental resonance frequencies is necessary to make a modal analysis. For an n-degree of freedom system, by Finite Element Method meshing (Fig. 1) the free motion equation of sample can be expressed as follows:

$$
[\mathbf{M}]\{\ddot{\mathbf{q}}\}+[\mathbf{C}]\{\dot{\mathbf{q}}\}+[\mathbf{K}]\{\mathbf{q}\}=\{\mathbf{0}\}
$$

where $\{\mathrm{q}\}$ is the vector of the displacement, and $[\mathrm{M}],[\mathrm{C}]$ and $[\mathrm{K}]$ are mass, damping and stiffness matrices, respectively. In this approach the mechanical system is modeled as Rayleigh damping which is associated with symmetric matrix [C] proportionally with $[\mathrm{M}]$ and $[\mathrm{K}]$ matrices.

\footnotetext{
*Corresponding author: pintiutza@gmail.com
} 


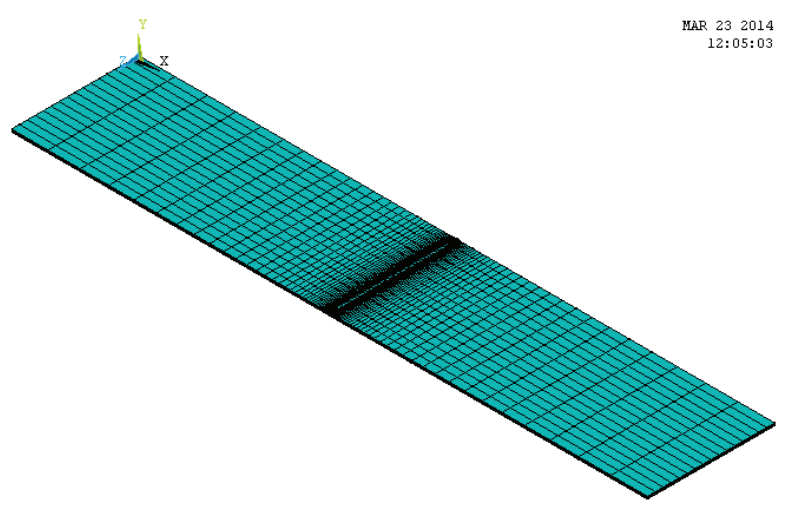

Fig. 1. Experimental stand for vibroacustic measurements

The resonance frequencies and modal shapes are obtained by Finite Element Analysis, using ANSYS [12].

\section{Experimental setup}

The experimental stand for non-contact measurement of free vibrations of the samples is shown in the Fig. 2. below, and it is composed by: the sample 1 , which is the mechanical structure to be analyzed; impulsive mini hammer 2; brackets to support the sample 3; elastic threads for support of the structure in boundary conditions with the free ends 4 ; the acoustic sensor one condenser microphone 5, and the computer that has embedded and acquisitions plate 6 .

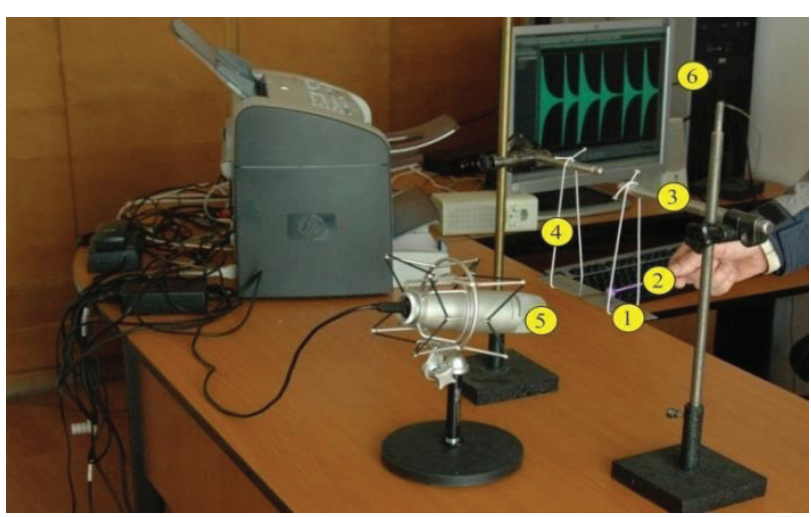

Fig. 2. Experimental stand for vibroacustic measurements

\section{Numerical results}

The sizes of laminate aluminum sample analyzed by ANSYS software are: $\mathrm{L}=206 \mathrm{~mm}, \mathrm{~b}=39.5 \mathrm{~mm}, \mathrm{~h}=1.5 \mathrm{~mm}$. The frequencies and the shape modes are given in Table I. This analysis is necessary to determine the order of the form of natural modes, that is, to determine which modes correspond to bending vibrations, respectively which modes correspond to torsional vibrations.
Table 1. The shape modes and their frequencies for laminate aluminum sample

\begin{tabular}{|c|c|}
\hline $\begin{array}{c}\text { Modes and } \\
\text { frequencies [Hz] }\end{array}$ & Shape mode \\
\hline $\begin{array}{c}\text { First bending } \\
\text { mode } \\
184.97 \mathrm{~Hz}\end{array}$ & \\
\hline $\begin{array}{c}\text { Second bending } \\
\text { mode }\end{array}$ & \\
$512.80 \mathrm{~Hz}$ & \\
\hline $\begin{array}{c}\text { First torsion } \\
\text { mode }\end{array}$ \\
$\begin{array}{c}578.18 \mathrm{~Hz} \\
\text { Third bending } \\
\text { mode } \\
1017.7 \mathrm{~Hz}\end{array}$ \\
\hline $\begin{array}{c}\text { Second torsion } \\
\text { mode }\end{array}$ \\
\hline
\end{tabular}

\section{Experimental results}

Equation (5) is used to determine the experimental values of the longitudinal elasticity module, E, with the frequencies corresponding to the first three bending modes of vibration, which are obtained from Fast Fourier Transform of the vibroacoutical signal obtained from experimental measurements. From Fig. 3, correlating with the results in Table 1 can determine the frequencies corresponding to the bending modes, respectively the torsion modes.

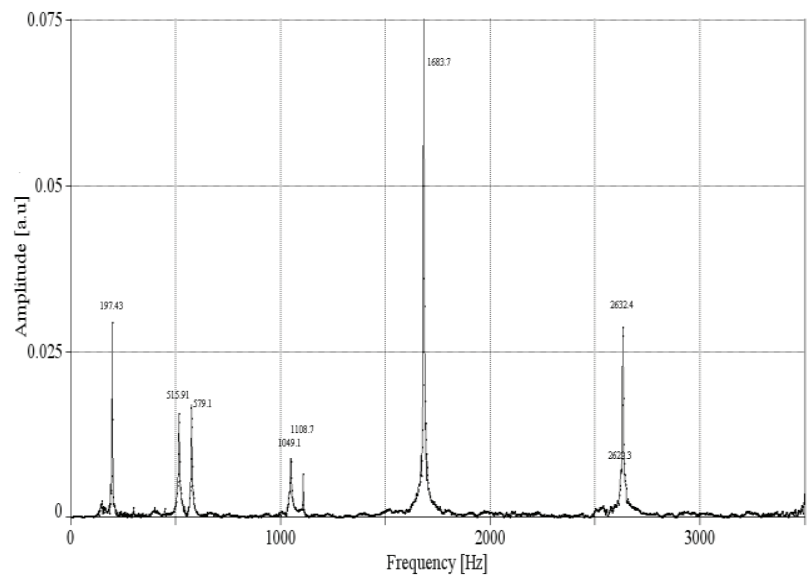

Fig. 3. Fourier Frequency Spectrum

The same formula is used to determine the experimental values of Young's modulus with frequencies determined by analyze the acquired signal with Prony's Series Method, D.J. Trudnowski [13].

Equation (6) is used to determine the experimental values of the shear modulus $G$, corresponding to the first two torsion modes of vibration, which are obtained also from Fast Fourier Transform, Fig. 3. 


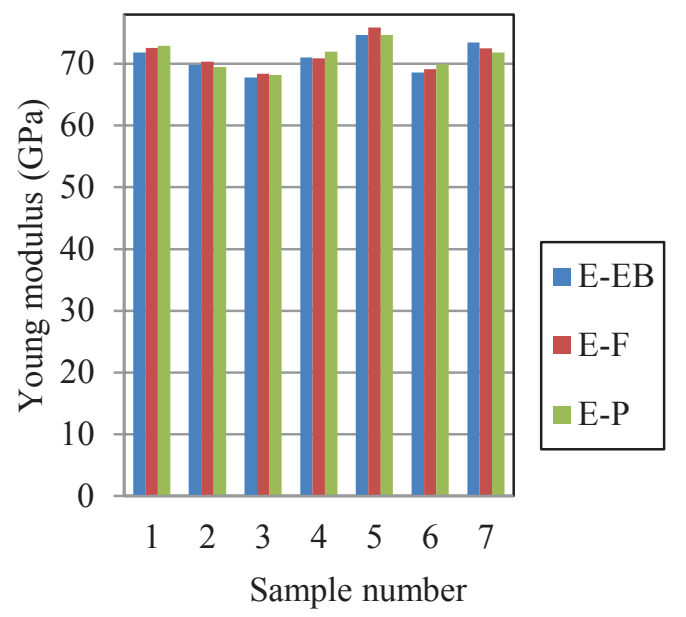

Fig. 4. Young's modulus (E) by different methods

The values of the modulus of elasticity obtained by three methods: Euler Bernoulli equation (E-EB), Fast Fourier Transform (E-F) and the series Prony method (EP), for seven samples are represented in Fig. 4.

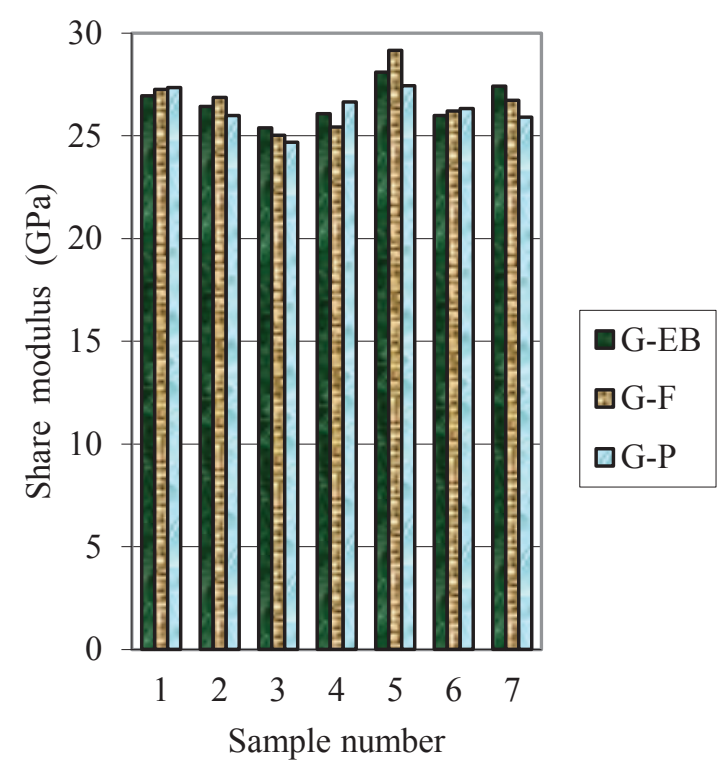

Fig. 5. Share modulus $(\mathrm{G})$ by different methods

The same three methods are used to determine the shear modulus of elasticity. Their values for seven samples of molten batches are shown in Fig. 5.

\section{Conclusion}

Method of measurement of Young's modulus, shear modulus and Poisson coefficient by modal analysis of vibrations excited by impulse is extremely simple to use.

The results for the elastic moduli are better than those obtained using standard tensile or shear tests.

This method does not require specific form for samples and does not introduce errors due to the fastening system.

Modulus variation depending on various alloying elements of aluminum, will be of particular interest and will constitute an upcoming issue.

\section{References}

[1] T. Anderson, "New developments within the Aluminum Shipbuilding Industry", Svetsaren, 58(1), pp. 3-5, 2003.

[2] K. Dudzik, "Mechanical Properties of 5083, 5059 and 7020 Aluminum Alloys and their Joints Welded by MIG", Journal of KONES Powertrain and Transport, 18(3), pp 1-5, 2011.

[3] SR EN 1706:2000, Aluminum and aluminum alloys. Molded pieces. Chemical composition and mechanical characteristics (Aluminiul şi aliaje de aluminiu. Piese turnate. Compoziţie chimică şi caracteristici mecanice, in romanian)

[4] R.Pradeep, B.S. Praveen Kumar, B. Prashanth, "Evaluation of mechanical properties of aluminum alloy 7075 , reinforced with silicon carbide and red mud composite", International Journal of Engineering Research and General Science, Vol. 2, Issue 6, pp. 1081-88, 2014.

[5] N. Bularda, T. Hepuț, „Mathematical modeling concerning the influence of chemical composition on the 6082 aluminum alloy on the phisical and mechanical characteristics", 12-th International Conference of Numerical Analysis and Applied Mathematics, 22-28 September 2014, Rhodos, Greece, Vol. 16482014.

[6] N.Bularda, T. Hepuţ, Reconditioning by welding of rims manufactured from nonferrous alloys, TIMA 1029, pp 61-66, 2014.

[7] M. Alfano, L. Pagnotta, "Recent Developments and Selected Patents on Vibration Based Methods for the Elastic Characterization of Isotropic Materials", Recent Pat on Mec. Eng. 2, pp 130-143, 2009.

[8] L. Bereteu, M. Vodă, Gh. Draganescu, "Measurement of Young's Modulus and Shear Modulus of some Structures Welded Using Flux Cored by Vibration Tests", Solid State Phenomena, Vol 216 pp 151-156, 2014.

[9] O. Suciu, L. Bereteu, Gh. Draganescu, Determination of Mechanical Properties of Hydroxyde Apatite Doped with Magnesium, AIP Conference Proceedings Vol 1564 pp. 132137, 2013.

[10] Simulation driven product development $\mid$ ANSYS, http://www.ansys.com., accessed on Mars 2017

[11] AutoSignal, Cutting edge signal analysis software http://www.sigmaplot.co.uk/products/autosignal/autosignal.php., accessed on Mars 2017

[12] L. Meirovitch, Fundamentals of Vibrations, Waveland Press, Inc. 2010

[13] D.J. Trudnowski, Characteristics of Identifying Linear Dynamic Models Response Data Using Prony Analysis, Battelle, 1992 